\title{
HISTOLOGIA E HISTOQUÍMICA DO MAGNO, UM DOS SEGMENTOS DO OVIDUTO DE NUMIDA MELEAGRIS (LINNÉ) (NUMIDIDAE, GALLIFORMES)
}

\author{
Maria das Graças Ribeiro ${ }^{1}$ \\ Maria Eloiza de Oliveira Teles ${ }^{1}$ \\ Sandra Maria das Graças Maruch ${ }^{1}$
}

\begin{abstract}
Histological and histochemical of the MAgnum, a SEgMENT of oVIDUCT OF NUMIDA MELEAGRIS (LINNÉ) (NUMIDIDAE, Galliformes). Numida meleagris (Linné, 1758) is an african bird that was brought to Brazil. As the bird adapted to the climate of this new habitat and spread all around the country, it is nowadays part of our avifauna. The present study continues topographic and morphofunctional researches on the female genital apparatus of this species, since it describes histological and histochemical aspects of magnum, a segment of oviduct. Magnum was dissected and processed according to routine and histochemical staining procedures to detect glycogen and mucous substances in the epithelial tissue and mucous glands. Besides focusing morphological aspects, the study compares the data obtained with those of other species aiming to contribute to the enlargement of the knowledge on reproductive biology of brazilian birds what may be important to make their biological control easier.
\end{abstract}

KEY WORDS. Galliformes, Numididae, female genital, oviduct, magnum

Ave campestre de origem africana, a galinha d'Angola Numida meleagris (Linné, 1758) (Fig. 1) é uma das espécies introduzidas no Brasil e que se adaptaram à avifauna brasileira, com ampla distribuição geoecológica. E apesar de serem consideradas aves exóticas (TOLEDo 1989) e acusadas de poluidoras sonoras (SICK 1984), as galinhas d'Angola têm sido bastante domesticadas em sítios e fazendas, sendo utilizadas na alimentação e no controle biológico de insetos, carrapatos, escorpiões, aranhas, protegendo a proximidade das residências.

Resistentes e ariscas, as galinhas d'Angola vivem em bandos e são poucos os registros, na literatura, de sua reprodução em cativeiro, dificultando o estudo da biologia de sua reprodução, principalmente considerando os aspectos morfofuncionais observados na fase de postura.

O interesse crescente pelo estudo da morfologia interna de Numida meleagris visa, além de contribuir para preencher a lacuna sobre tais informações, raras e esparsas na literatura, fornecer subsídios para o conhecimento de suas relações e influência sobre o ambiente e avifauna brasileiros (PEREIRA et al. 1994; RIBEIRO et al. 1995).

1) Departamento de Morfologia, Instituto de Ciências Biológicas, Universidade Federal de Minas Gerais. Avenida Antônio Carlos 6627, Caixa Postal 4045, 31250-970 Belo Horizonte, Minas Gerais, Brasil. 
O presente artigo, que descreve o estudo morfológico e histoquímico do magno, um dos segmentos do oviduto de Numida meleagris, é parte de projeto de estudo sobre os sistemas genitais feminino e masculino desta espécie, com vistas à ampliação do conhecimento sobre a biologia da reprodução de aves brasileiras ou aqui introduzidas.

\section{MATERIAL E MÉTODOS}

Para este trabalho foram utilizadas seis fêmeas (três jovens e três adultas em fase de postura) de Numida meleagris. Os animais foram sacrificados e submetidos a incisão longitudinal mediana ventral para estudo dos aspectos anatomotopográficos do sistema genital e posterior dissecação do oviduto.

Para estudo histológico, fragmentos do magno foram fixados em solução de Bouin e Helly (LILLIE \& FULMER 1976), incluídos em parafina e processados conforme as técnicas histológicas de rotina: colorações em hematoxilina e eosina, azan e tricrômico de Gomori; método de Weigert (modificado por NOGUEIRA \& RIBEIRO 1980) para fibras elásticas e técnica de Gomori (GOMORI 1952), para fibras reticulares.

Para estudo histoquimico foram utilizados os métodos de Periodic Acid Shiff (PAS), alcian blue (AB) a pH 0.5 e 2.5 (LILLIE 1954) para deteç̧ão de glicogênio e mucossubstâncias em células epiteliais de revestimento e em glândulas da lâmina própria, além da técnica de von Kossa (LILLIE 1954) para possível identificação de cálcio. 2.000 .

Os resultados foram analisados e fotografados ao microscópio Leica ACT

\section{RESULTADOS}

O oviduto de Numida meleagris é um ducto longo e sinuoso, constituído de regiões anatômica e histologicamente distintas e cujas diferenças se tornam mais acentuadas em fêmeas adultas, em fase de postura. O magno é o maior e mais espiralado dos segmentos do oviduto e limita-se cranialmente com o infundíbulo e caudalmente com o istmo (Fig. 2). No período de postura, apresenta coloração branco leitosa e sua parede, mais espessa que a do infundíbulo, mostra numerosas pregas, vistas a olho nu: pregas altas, largas, que praticamente obliteram o lume (Fig. 3). Tais aspectos são observados no magno de fêmeas adultas, em fase secretora, quando as glândulas da mucosa se encontram bastante desenvolvidas.

Histologicamente o magno apresenta túnica mucosa ricamente pregueada (Fig. 3). As pregas descritas como primárias são longitudinais e ocupam grande parte da luz. As pregas secundárias são menores, mais rasas e se apresentam, às vezes, como invaginações das pregas primárias. O epitélio de revestimento é simples prismático, constituído de dois tipos celulares (Figs 4-5): células ciliadas, com núcleos ovais, vesiculosos e células secretoras de sialomucinas, $\mathrm{PAS}$ e $\mathrm{AB}$ positivas em $\mathrm{pH} 0,5$ e 2,5, com núcleos esféricos ou alongados, localizados no terço basal das células. 

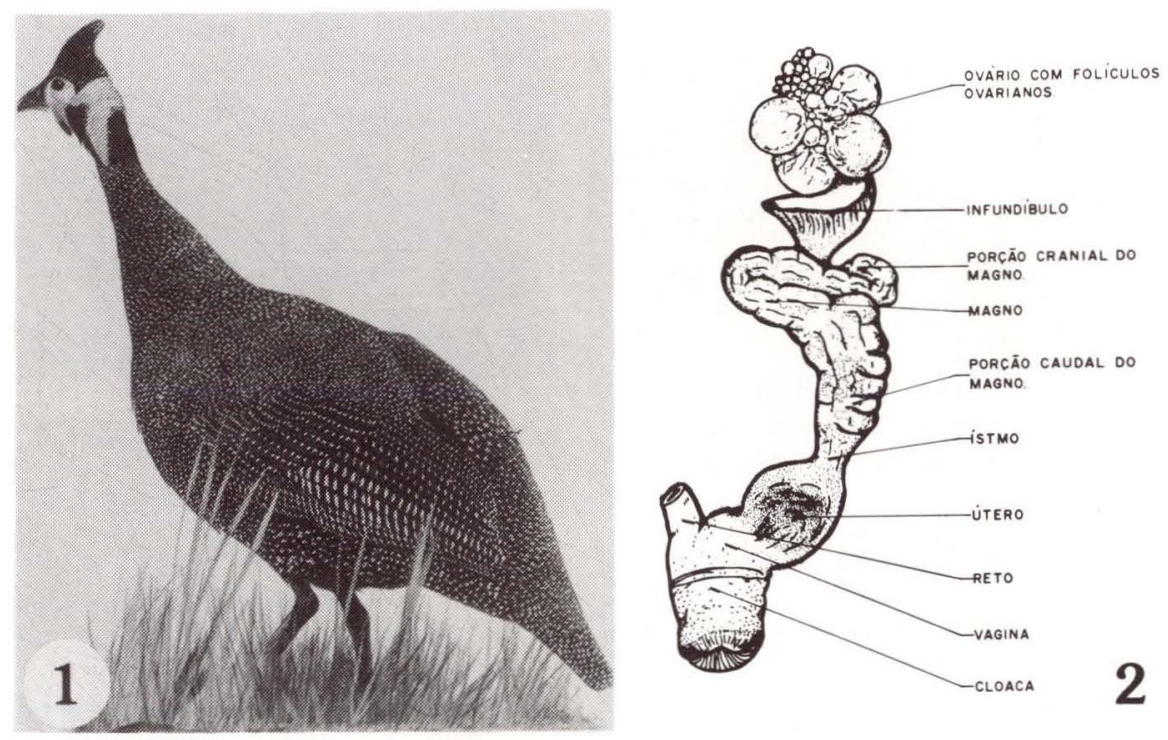

Figs 1-2. (1) Numida meleagris (galinha d'Angola); (2) esquema do oviduto esquerdo.

A lâmina própria é de tecido conjuntivo frouxo, rico em substância fundamental amorfa, poucas células, delicadas fibras colágenas, poucas fibras elásticas e rica rede de fibras reticulares, envolvendo e sustentando as numerosas glândulas da mucosa (Figs 6-7). Estas glândulas são tubulosas, ramificadas e preenchem quase que totalmente a lâmina própria (Fig. 4), abrindo-se na base das pregas, sem formar ductos típicos. Os adenômeros glandulares apresentam-se constituídos por uma única camada de células cúbicas, com citoplasma de aspecto finamente granular e reação negativa ao $\mathrm{PAS}, \mathrm{AB}$ e também à técnica de von Kossa.

Abaixo das pregas da mucosa observa-se delicada faixa de tecido conjuntivo frouxo bem vascularizado, mostrando riqueza de fibras reticulares, principalmente concentradas nas paredes dos vasos sanguíneos.

A túnica muscular apresenta duas camadas de fibras musculares lisas, a interna circular e a externa longitudinal, separadas por um tecido conjuntivo frouxo, pouco celular, rico em vasos sanguíneos. Externamente encontra-se a túnica serosa, constituída de tecido conjuntivo frouxo e mesotélio.

Em fêmeas jovens de Numida meleagris, o magno apresenta mucosa com pregas mais estreitas, revestidas por epitélio simples prismático, mostrando reação negativa ao PAS e AB. 
A lâmina própria é preenchida por tecido conjuntivo frouxo, bastante celular em sua região adjacente ao epitélio. As glândulas estão praticamente ausentes, mostrando início de sua histogênese em algumas pregas.
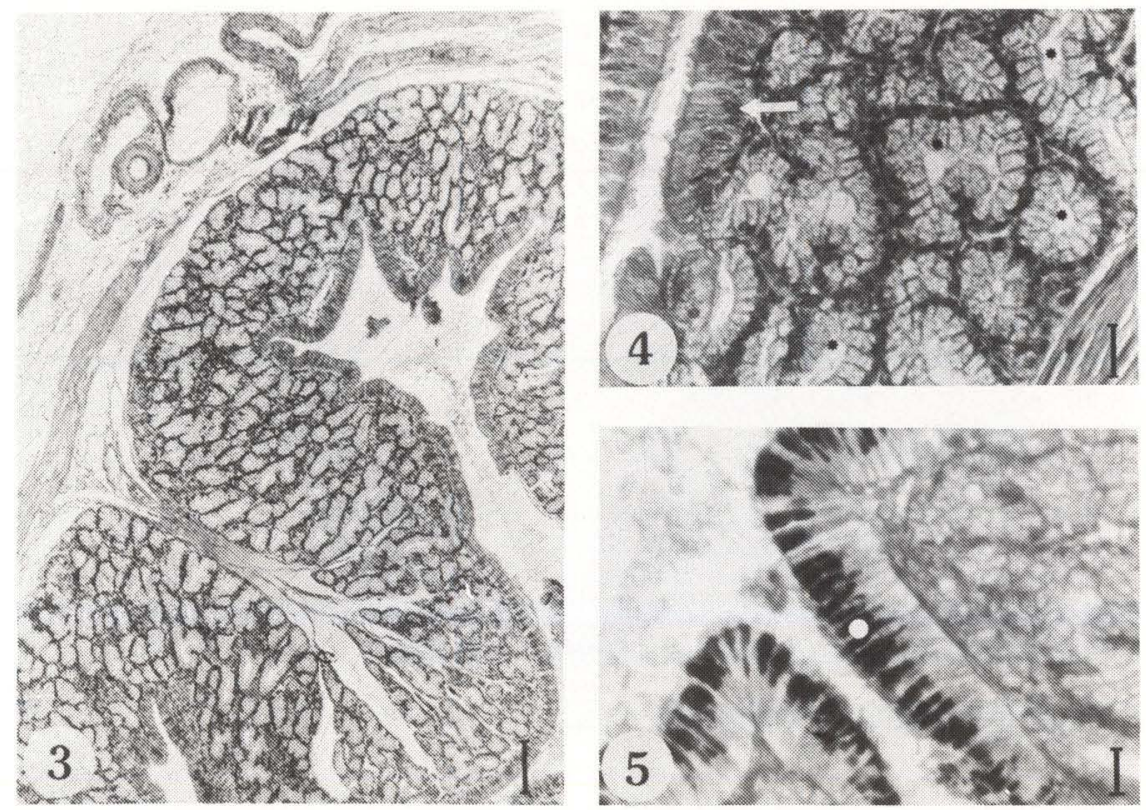

Figs 3-5. Aspecto morfológico do magno. (3) Visão geral da parede do magno destacando as pregas da mucosa $(\mathrm{HE}$, barra $=100 \mu \mathrm{m}) ;(4)$ corte histológico destacando o epitélio de revestimento (seta) e a riqueza de glândulas da lâmina própria $\left(^{*}\right)$ (Tricrômico de Gomori, barra $=20 \mu \mathrm{m}) ;(5)$ parte do epitélio de revestimento, destacando as células secretoras PAS positivas (barra $=20 \mu \mathrm{m})$.

\section{DISCUSSÃO}

Sendo o magno das várias espécies de aves estudadas, o mais extenso dos segmentos do oviduto, é também a porção que mais contribui na produção das secreções que são adicionadas ao ovo, quando de sua passagem pelo oviduto (BRADLEY 1950; BANKS 1974; GILBERT 1979; KING 1981; DYCE et al. 1990). Estas observações foram feitas também em Numida meleagris, em fase de postura.

Acentuadas diferenças morfológicas foram descritas no magno de Numida meleagris, baseadas em observações macroscópicas e à microscopia óptica, entre fêmeas jovens e aquelas em fase de postura. As células secretoras do epitélio de revestimento são mais volumosas nesse período; as pregas da mucosa são bem mais desenvolvidas e as glândulas ocupam grande parte da lâmina própria. Dados semelhantes foram descritos em galinha doméstica, por BRADLEY (1950), BANKS (1974) e DYCE et al. (1990). 

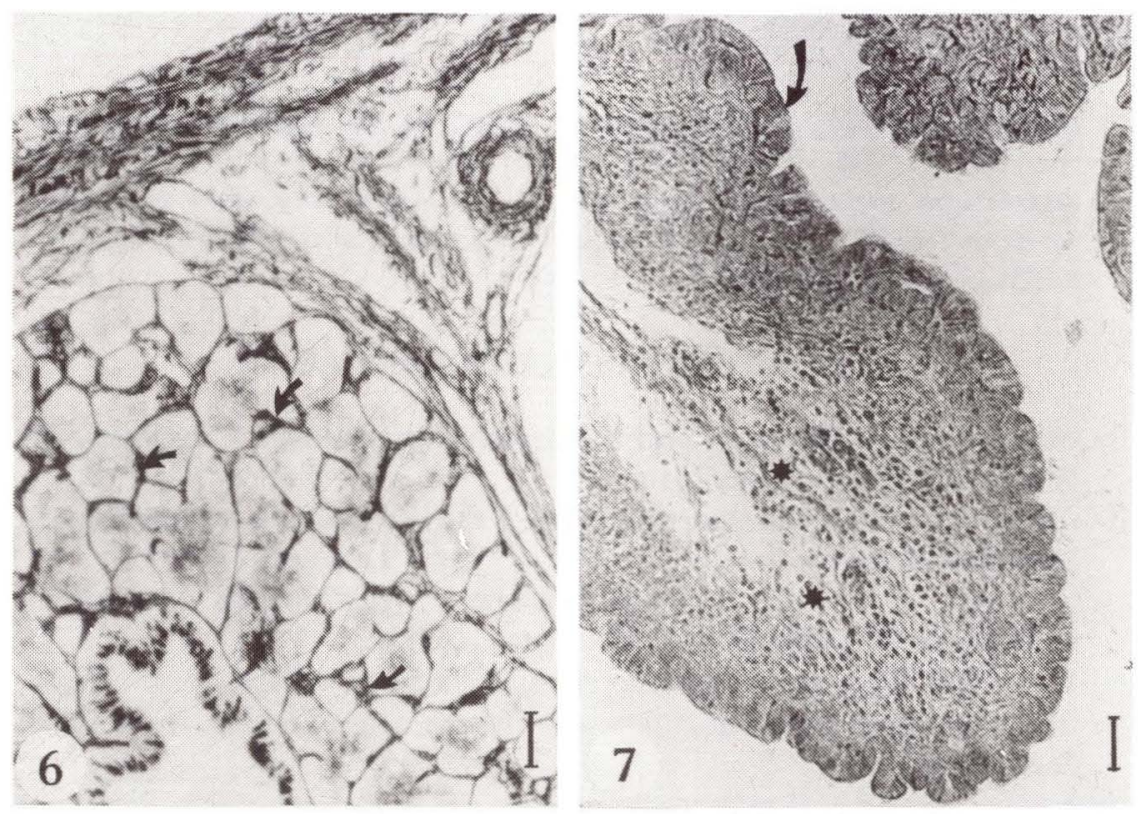

Figs 6-7. Corte histológico do magno de Numida meleagris. (6) trama de fibras reticulares (setas) envolvendo principalmente as glândulas na lâmina própria (Gomori, barra $=50 \mu \mathrm{m}$ ); (7) epitélio de revestimento do magno de fềmea jovem (setas), evidenciando a escassez de glândulas na lâmina própria $(*)(\mathrm{HE}$, barra $=100 \mu \mathrm{m})$.

Segundo FUJII (1981), o epitélio de revestimento do magno de galinha doméstica é constituído de células ciliadas e não ciliadas. OGWUEGBU \& AIRE (1990), estudando a ultraestrutura do magno de Numida meleagris galeata, descreveram, além desses dois tipos celulares, um terceiro tipo constituído de células secretoras cuboidais, consideradas glândulas tubulares. O citoplasma apical destas células apresenta numerosos grânulos de secreção, com aspecto homogêneo. RICHARDSON (1935) e BRADLEY (1950) observaram a presença de células ciliadas e células secretoras, semelhantes ao que foi observado no magno de Numida meleagris. No entanto, a reação positiva das células secretoras ao PAS e ao $\mathrm{AB}$ em $\mathrm{pH}$ o,5 e 2,5 não foi citada por outros autores. A continuação das pesquisas para esclarecimento do comportamento celular do epitélio de revestimento do magno é meta dos próximos trabalhos.

As numerosas glândulas tubulares ramificadas, observadas no magno de Numida meleagris também foram descritas por BRADLEY (1950) em galinha doméstica e BANKS (1974) em outras espécies de aves. No entanto, a reação negativa ao $\mathrm{PAS}$, ao $\mathrm{AB}$ e à técnica de von Kossa observada nas células glandulares da mucosa aponta para a necessidade de pesquisas histoquímicas com métodos mais amplos, nesta e em outras espécies de aves, sobre o papel destas glândulas na elaboração da secreção dos componentes do ovo, em seu trajeto pelo magno. 
As túnicas muscular e serosa do magno obedecem ao padrão histológico descrito em outras espécies de aves.

AGRADECIMENTOS. As autoras agradecem ao Prof. Ney Eny Demas Carnevalli, pela confirmação da espécie em estudo; à tradutora Maria da Glória A. Ferreira; à bióloga Sandra Resende Lima, responsável pela preparação técnica do material estudado e à técnica do laboratório fotográfico Ivone Carmo de Oliveira. Agradecem, ainda, à PRPq/UFMG e à FAPEMIG, pelo auxilio financeiro.

\section{REFERÊNCIAS BIBLIOGRÁFICAS}

BANKS, W.J. 1974. Histology and comparative organology: a text atlas. The Williams \& Williams Co., 261p.

BRADLEY, O.C. 1950. The structure of Fowl: the reproductive organs. London, Lippincott, 128p.

DYCE, K.M.; W.O. SACK \& C.J.G. Wensing. 1990. Tratado de anatomia veterinária. Philadelphia, W.B. Saunders Co., 555p.

FUJII, S. 1981. Histological and histochemical studies on oviduct of the domestic fowl with special reference to the region of uterovaginal juncture. Arch. Histol. Jap. 23 (5): 447-459.

Gilbert, A.B. 1979. Female genital organs. In: A.S. KING (Ed.). Form and function in birds. London, Academic Press, 360p.

GOMORI, G. 1952. Microscopic Histochemistry Principles and Pratice. Chicago, University of Chicago Press, 480p.

KING, A.S. 1981. Aparelho urogenital das aves; órgãos genitais femininos. In: R. GetTy. 1981. Anatomia dos Animais Domésticos. Rio de Janeiro, Interamericana, $1813 \mathrm{p}$.

LILliE, R.D. 1954. Histopatologic Technic and Practical Histochemistry. New York, Blakiston Company, 501p.

Lillie, R.D. \& H.M. Fulmer. 1976. Histopatologic Technic and Practical Histochemistry. New York, McGraw-Hill, 942p.

NogueIRA, J.C. \& R.D. Ribeiro. 1980. A simplified Weigert's method for staining elastic fibers. Arq. Esc. Vet. Univ. Minas Gerais 32: 333-335.

PEREIRA, K.S.; S.M.G. MARUCH; M.G. Ribeiro \& M.E. TeleS. 1994. Morfologia do testículo de Numida meleagris (Linné, 1758) Numididae-Galliformes. Rev. Bios 1 (2): 14-24.

Ogwuegbu, S.O. \& T.A. Aire. 1990. Ultrastructural studies of the magnum and isthmus of the active of indigenous helmeted guinea fowl (Numida meleagris galeata, Pallas). Veterinarski Arhiv. 60 (2): 101-108.

RibeIRO, M.G.; S.M.G. MARUCH \& M.E.O. TELES. 1995. Estudo histológico e histoquímico do oviduto de Numida meleagris (Linné, 1758) com referência ao útero. Rev. Bios 2 (3): 35-40.

RICHARDSON, K.C. 1935. The secretory phenomena in the oviduct by microcineration techinique. Phil. Trans. Roy. Soc. 225 (B): 149-195. 
SICK, H. 1984. Ornitologia brasileira: uma introdução. Brasília, Universidade de Brasília, 480p.

TolEDO, L.R. 1989. Angola-nobre como o faisão. Rev. Globo Rural Econ. 11: 90-95.

Recebido em 13.VI.1996; aceito em 15.V.1997. 